\title{
Validating a self-report measure of HIV viral suppression: an analysis of linked questionnaire and clinical data from the Canadian HIV Women's Sexual and Reproductive Health Cohort Study
}

\author{
Allison Carter ${ }^{1,2}$, Alexandra de Pokomandy ${ }^{3,4}$, Mona Loutfy 5,6 , Erin Ding 2 , Paul Sereda², Kath Webster ${ }^{1}$, \\ Valerie Nicholson ${ }^{1}$, Kerrigan Beaver ${ }^{5}$, Robert S. Hogg ${ }^{1,2}$, Angela Kaida ${ }^{1 *}$ and On Behalf of the CHIWOS \\ Research Team
}

\begin{abstract}
Background: We assessed the validity of a self-report measure of undetectable viral load (VL) among women with HIV in British Columbia (BC), Canada. Questionnaire data from the Canadian HIV Women's Sexual and Reproductive Health Cohort Study was linked with population-based clinical data from the BC Centre for Excellence in HIV/AIDS. Self-reported undetectable VL was assessed by the question: "What was your most recent $V L$, undetectable (i.e. $<50$ copies $/ \mathrm{mL}$ ) or detectable (i.e. $\geq 50$ copies $/ \mathrm{mL}$ )?" Laboratory measurements of $\mathrm{VL}<50$ copies $/ \mathrm{mL}$ (closest to/before study visit) were the criterion for validity analyses. We measured positive and negative predictive values (PPV, NPV) and likelihood ratios (LR+, LR-).

Results: Of 356 participants, $99 \%$ were linked to clinical data. Those unlinked $(n=1)$, missing self-report $V L(n=18)$, or missing self-report and laboratory VL $(n=1)$ were excluded. Among the remaining 336: median age was 44 (IQR 37-51); 96\% identified as cis-gender; 84\% identified as heterosexual; and 45\% identified as Indigenous, 40\% White, 8\% African, Caribbean, or Black, and 8\% other/multiple ethnicities. Overall, $85 \%$ self-reported having an undetectable VL while $82 \%$ had clinical data indicating viral suppression. The PPV was 93.7 (95\% Cl 90.2-96.2) indicating that 94\% of women who self-reported being undetectable truly were. The NPV was 80.4 (95\% Cl 66.9-90.2). LR+ was 3.2 (2.1-4.6) and LR - was $0.05(0.03-0.10)$.
\end{abstract}

Conclusions: Our self-report measure assessing undetectable VL strongly predicted true viral suppression among Canadian women with HIV. This measure can be used in research settings without laboratory data in regions with high rates of $V L$ testing and suppression.

Keywords: Women, HIV, Viral suppression, Validation, Canada, CHIWOS

\section{Background}

Combination antiretroviral therapy (cART) is now recommended for all people living with HIV regardless of CD4 cell count [1]. The clinical benefit of early initiation

\footnotetext{
*Correspondence: kangela@sfu.ca

1 Faculty of Health Sciences, Simon Fraser University, Burnaby, BC, Canada Full list of author information is available at the end of the article
}

of cART was established in two recent randomized controlled trials, START [2] and Temprano [3], which reported reduced risks of HIV morbidity and mortality. Sustained use of and adherence to cART also has the additional benefit of lowering the risk of HIV transmission to zero by suppressing plasma viral load (VL) [4-9].

The efficacy of using treatment for individual health and for population-level prevention has been 
demonstrated in jurisdictions around the world including British Columbia (BC), Canada, where "Treatment as Prevention" (TasP) was formally adopted into policy in 2010 [10]. This has resulted in new global targets for reducing the burden of HIV worldwide. According to United Nations three-part "90-90-90" strategy, the goal is to have, by $2020,90 \%$ of all people living with HIV diagnosed, $90 \%$ of all people diagnosed with HIV on cART, and $90 \%$ of all people on cART virally suppressed [11].

To monitor and evaluate progress on $90-90-90$ goals, accurate assessment of viral suppression is essential. Laboratory technologies of plasma samples are the gold standard for measuring VL in clinical practice [12]. However, in the absence of linkage to clinical data, observational studies must rely on participant self-report of VL and it is unclear whether this is a valid method of assessment. In this analysis, we investigated the validity of using a brief survey question capturing most recent VL as a way to estimate viral suppression among a cohort of women living with $\mathrm{HIV}$ in $\mathrm{BC}$, using linked questionnaire and clinical data from the Canadian HIV Women's Sexual and Reproductive Health Cohort Study (CHIWOS).

\section{Methods}

\section{The study}

CHIWOS is a national, multi-site, longitudinal, community-based research study conducted by, with, and for women living with HIV, in collaboration with researchers, clinicians, service providers, policy-makers and other stakeholders (described in detail elsewhere: [13]). In total, 1425 self-identified women living with HIV ( $\geq 16$ years) were enrolled into the study from three Canadian provinces: BC $(\mathrm{n}=356)$, Ontario $(\mathrm{n}=713)$, and Québec $(\mathrm{n}=356)$.

\section{Procedures}

Participants completed structured questionnaires at baseline, administered by Peer Research Associates (women living with HIV who have received training in community-based research) [14]. Study visits were 1.5 to $2.5 \mathrm{~h}$ long (median: $120 \mathrm{~min}$, IQR 90-150) and took place in various community settings such as HIV clinics, AIDS Service Organizations, women's homes, or via phone/Skype [15]. Questionnaires were web-based, developed using FluidSurveys ${ }^{\mathrm{TM}}$ software and designed to collect nationally consistent self-reported data on sociodemographics, use of HIV clinical and support services, and health outcomes including most recent VL. In BC, linkage to clinical data was possible through the Drug Treatment Program (DTP) of the BC Centre for Excellence in HIV/AIDS, a population-based registry capturing $100 \%$ of laboratory-confirmed VL data for all people living with HIV and receiving cART in BC. Linkage will be endeavored in other study provinces via the Canadian HIV Cohort (CANOC) Collaborative Research Centre [16], although incomplete linkage is expected due to varying study eligibility criteria and the absence of a single, coordinated population-based registry in Ontario and Québec.

\section{Final sample for this analysis}

For this analysis, we used baseline questionnaire data from participants enrolled in CHIWOS in BC between August 27, 2013 and May 1, 2015, and linked clinical data from the BC Centre for Excellence in HIV/AIDS. Of 356 participants, $99 \%$ were linked to the DTP clinical database $(\mathrm{n}=354)$. Those who remained unlinked $(\mathrm{n}=1)$, who provided invalid responses (i.e., "don't know" or "prefer not to answer") to the survey question assessing VL or self-reported never receiving HIV medical care or VL results $(n=18)$, or who were missing both self-reported and laboratory VL $(n=1)$ were excluded from the analysis, leading to a final analytic sample of 336.

\section{Main outcome}

In the CHIWOS questionnaire, self-reported VL was assessed by the following survey question: "What was your most recent viral load, undetectable (i.e. below 50 copies/mL) or detectable (i.e. 50 copies/mL or more)?" Criteria for validity analyses were corresponding laboratory measurements of $\mathrm{VL}<50$ copies $/ \mathrm{mL}$, with tests closest to and before the study visit selected for analysis. For those included in analyses $(\mathrm{N}=336)$, median time between study visit and most recent VL lab result was 50.5 days (IQR 20.5-87).

\section{Statistical analyses}

Baseline characteristics of the sample were estimated. Following this, positive and negative predictive values (PPV, NPV) and likelihood ratios (LR+, LR-) were computed for the outcome, overall and stratified by select socio-demographic variables including ethnicity (Indigenous vs. White vs. African, Caribbean, or Black vs. other/multiple ethnicities), education ( $<$ High school vs. $\geq$ High school), and illicit drug use within the past 3 months (Yes vs. No). PPV is the probability that participants who self-report being "undetectable (i.e., below 50 copies $/ \mathrm{mL}$ )" truly have laboratory measurements of VL $<50$ copies $/ \mathrm{mL}$, while NPV is the probability that participants who self-report being "detectable (i.e., above 50 copies $/ \mathrm{mL}$ )" truly have laboratory measurements of $\mathrm{VL} \geq 50$ copies/mL [17]. LR+ (sensitivity/1-specificity) corresponds to the clinical concept of "ruling-in disease", and indicates how much a "positive test" (in this case, self-reported undetectable VL) increases the odds that a 
patient actually has the health outcome (in this case, true suppression) [18]. LR - (1-sensitivity/specificity) corresponds to "ruling-out disease", and indicates how much a "negative test" (in this case, self-reported detectable VL) decreases the odds that a patient has the health outcome (in this case, true suppression) [18]. LRs greater than 1 indicate that true suppression is likely (the larger the number, the more likely suppression), while LRs between 0 and 1 indicate that suppression is unlikely (the closer the number to zero, the less likely suppression) [18]. Analyses were conducted using SAS version 9.4 (SAS, North Carolina, United States).

\section{Ethical statement}

All Principal Investigators' institutional Research Ethics Boards granted ethical approval including Women's College Hospital, McGill University Health Centre, and in BC, Simon Fraser University and the University of British Columbia/Providence Health (ethical approval numbers: 2012s0959 and H12-03326). Ethical approval was also sought and granted from hospitals and AIDS Service Organizations if recruitment occurred there. All participants provided consent (written or oral in the case of phone interviews) to participate.

\section{Results}

\section{Baseline characteristics of the sample}

Among the 336 women included in this analysis, 99\% self-reported accessing HIV medical care in the past year and $96 \%$ self-reported currently taking cART. Overall, 85\% $(\mathrm{n}=286)$ self-reported having undetectable VL and $82 \%(\mathrm{n}=276)$ had laboratory data indicating $\mathrm{VL}<50$ copies/mL.

Baseline characteristics of the sample are provided in Table 1. Median age was 44 (IQR 37-51). The majority of women identified as cis-gender (96\%) and heterosexual (84\%). Forty-five percent identified as Indigenous and $40 \%$ as White; a small proportion also identified as African, Caribbean, or Black (8\%), or other/multiple ethnicities (8\%). Most completed at least high school (73\%) yet reported low annual household incomes of $<\$ 20,000$ (72\%). Thirty-four percent reported illicit drug use in the past 3 months, and $9 \%$ were incarcerated in the past year.

\section{Validity analyses of viral load data taken from questionnaires and laboratory results}

Results of validity analyses are provided in Tables 2 (overall sample) and 3 (sub-populations). For the overall sample, the PPV was 93.7 (95\% CI 90.2-96.2), indicating that $93.7 \%$ of women who self-reported being undetectable via questionnaire truly were virally suppressed according to laboratory results. The NPV was 80.4 (95\% CI 66.9-90.2), suggesting that $80.4 \%$ of women who
Table 1 Baseline characteristics of women with HIV enrolled in British Columbia in the CHIWOS Study $(n=336)$

\begin{tabular}{|c|c|}
\hline & n (\%) \\
\hline \multicolumn{2}{|l|}{ Clinical variables } \\
\hline Self-reported HIV medical care in past year (yes) & $333(99)$ \\
\hline Self-reported current cART use (yes) & $323(96)$ \\
\hline Self-reported undetectable VL (yes) & $286(85)$ \\
\hline Laboratory-confirmed VL <50 copies/mL (yes) & $276(82)$ \\
\hline \multicolumn{2}{|l|}{ Socio-demographic variables } \\
\hline Age, median (IQR) & $44(\operatorname{QQR} 37-51)$ \\
\hline \multicolumn{2}{|l|}{ Gender identity } \\
\hline Cis gender & $323(96)$ \\
\hline Trans and gender diverse women & $13(4)$ \\
\hline \multicolumn{2}{|l|}{ Sexual orientation } \\
\hline Heterosexual & $281(84)$ \\
\hline LGBTQ & $55(16)$ \\
\hline \multicolumn{2}{|l|}{ Ethnicity } \\
\hline Indigenous & $151(45)$ \\
\hline White & $133(40)$ \\
\hline African/Caribbean/Black & $26(8)$ \\
\hline Other ethnicities & $26(8)$ \\
\hline$\geq$ High school education (yes) & $245(73)$ \\
\hline$<\$ 20,000$ annual household income (yes) & $243(72)$ \\
\hline Illicit drug use in past 3 months (yes) & $113(34)$ \\
\hline
\end{tabular}

$V L$ viral load, $C A R T$ combination antiretroviral therapy, LGBTQ lesbian/gay/ bisexual/two-spirited/queer, CHIWOS Canadian HIV Women's Sexual and Reproductive Health Study

self-reported being detectable truly were not virally suppressed according to laboratory results. The $\mathrm{LR}+$ was 3.2 (95\% CI 2.1-4.6), indicating that self-reporting undetectable offers a moderate increase in the likelihood of true suppression. The LR - was 0.05 (95\% CI 0.03-0.10), suggesting that reporting a detectable VL provides a large and conclusive decrease in the likelihood of true suppression. In terms of specific sub-populations, no significant differences in PPVs were observed, with point estimates ranging from 90.4 to 96.0 (and overlapping confidence intervals) across select socio-demographic variables including ethnicity, education, and recent illicit drug use. Some variations in point estimates, though, were seen in NPVs. For instance, those who had completed high school had a higher NPV [84.4 (95\% CI 67.2-94.7)] compared with those who did not [73.7 (95\% CI 48.8-90.9)]; while the confidence intervals were large and overlapped owing to small cell sizes and low power, the differing effect estimates suggest education level may be a marker for accurate reporting of detectable VL. Illicit drug use was not a marker, however. The values of likelihood ratios (LR+ and LR-) were similar to those found with the overall sample. 
Table 2 Predictive values and likelihood ratios of self-reported undetectable VL in overall CHIWOS cohort $(n=336)$

\begin{tabular}{|c|c|c|c|c|c|c|}
\hline & & & $\operatorname{PPV}(95 \% \mathrm{Cl})$ & $\operatorname{NPV}(95 \% \mathrm{Cl})$ & $\mathrm{LR}+(95 \% \mathrm{Cl})$ & $\mathrm{LR}-(95 \% \mathrm{Cl})$ \\
\hline & \multicolumn{6}{|c|}{ Laboratory-confirmed VL (from BC-CfE)a } \\
\hline & VL <50 copies/mL & $\mathrm{VL} \geq 50$ copies $/ \mathrm{mL}$ & & & & \\
\hline \multicolumn{7}{|l|}{ Self-report VL (from CHIWOS) } \\
\hline Undetectable (i.e. <50 copies/mL) & 267 & 18 & $93.7(90.2-96.2)$ & $80.4(66.9-90.2)$ & $3.2(2.1-4.6)$ & $0.05(0.03-0.10)$ \\
\hline Detectable (i.e. $\geq 50$ copies/mL) & 10 & 41 & & & & \\
\hline
\end{tabular}

Table 3 Predictive values and likelihood ratios of self-reported undetectable VL in CHIWOS sub-populations ( $\mathrm{n}=336$ )

\begin{tabular}{|c|c|c|c|c|}
\hline & $\operatorname{PPV}(95 \% \mathrm{Cl})$ & NPV $(95 \% \mathrm{Cl})$ & $\mathrm{LR}+(95 \% \mathrm{Cl})$ & $\mathrm{LR}-(95 \% \mathrm{Cl})$ \\
\hline \multicolumn{5}{|l|}{ Ethnicity } \\
\hline Indigenous & $92.6(86.4-96.5)$ & $86.7(69.3-96.2)$ & $3.8(2.1-6.6)$ & $0.05(0.02-0.12)$ \\
\hline Caucasian & $94.8(89.1-98.1)$ & $70.6(44.0-89.7)$ & $2.9(1.5-5.5)$ & $0.07(0.03-0.16)$ \\
\hline African/Caribbean/Black & $91.3(72.0-98.9)$ & $100.0(29.2-100.0)$ & $2.5(0.8-7.3)$ & NA \\
\hline Other & $96.0(79.6-99.9)$ & $0(0-97.5)$ & $1.0(0.9-1.0)$ & NA \\
\hline \multicolumn{5}{|l|}{ Education } \\
\hline$<$ High school & $91.4(82.3-96.8)$ & $73.7(48.8-90.9)$ & $3.1(1.6-6.1)$ & $0.10(0.04-0.25)$ \\
\hline$\geq$ High school & $91.4(82.3-96.8)$ & $84.4(67.2-94.7)$ & $3.4(2.1-5.6)$ & $0.03(0.01-0.08)$ \\
\hline \multicolumn{5}{|c|}{ Illicit drug use in past 3 months } \\
\hline Yes & $90.4(81.9-95.8)$ & $80.0(61.4-92.3)$ & $3.7(2.0-6.8)$ & $0.10(0.04-0.22)$ \\
\hline No & $95.0(91.0-97.6)$ & $80.1(58.1-94.6)$ & $2.6(1.6-4.3)$ & $0.03(0.01-0.09)$ \\
\hline
\end{tabular}

PPV positive predictive value, NPV negative predictive value, $L R+$ positive likelihood ratio, $L R-$ negative likelihood ratio, $95 \% C I 95$ percent confidence interval, $V L$ viral load, CHIWOS Canadian HIV Women's Sexual and Reproductive Health Cohort Study

\section{Discussion}

Our findings demonstrate that a brief survey question measuring self-reported undetectable VL strongly predicted true viral suppression, as confirmed via laboratory results, among a cohort of women living with HIV in BC, Canada. The PPV was high $(>90)$ and the LR+ greater than 1, both for the overall sample and for specific subpopulations, suggesting that this self-report measure is a valid method of assessment of undetectable $\mathrm{VL}$ among diverse communities of women living with HIV where $\mathrm{VL}$ testing is common and the true prevalence of viral suppression is high (i.e., $82 \%$ were undetectable as measured through laboratory data). The NPV was lower in comparison (ranging from 70 to 100 depending on the demographic group) but the LR- was extremely close to zero, suggesting that for participants who reported being detectable, we can have high confidence that this selfreport is accurate and the participant is not suppressed.

Jurisdictions around the world are currently implementing policy and programmatic interventions to meet the United Nation's 90-90-90 targets, which aim to have $73 \%$ of all people living with HIV virally suppressed by
2020 [11]. This goal has both individual and public health value, with HIV viral suppression achieved through early and sustained use of cART consistently shown to be associated with reduced disease progression, extended life expectancy, and zero risk of onward transmission [2-9]. Measuring progress on achieving suppression in research settings is important but may be challenged by a lack of clinical data. We experienced this in CHIWOS, where only one of our three study provinces currently has laboratory data available through linkage with a populationbased clinical registry.

As shown in this study, $82 \%$ of women living with HIV in BC had an undetectable VL, defined in this study as below 50 copies $/ \mathrm{mL}$, which exceeds the United Nation's 90-90-90 targets. Our threshold for designating a VL as undetectable was stricter than some studies (i.e., that use 300 to 500 copies/mL [19]), but this cut-off is consistent with past reporting in Canada [20,21], and even with this conservative measure, the prevalence of HIV suppression was high and comparable to observational data from other cohorts of women living with HIV [22, 23]. Moreover, based on the positive and negative predictive values 
and likelihood ratios, the majority of women were able to accurately report their VL. This self-reported measure can, therefore, be used in research settings without laboratory data confirmation and where VL testing and the true prevalence of viral suppression is high to assess 90-90-90-related goals.

There are limitations to this study. We were unable to validate this measure across all study provinces and women in different regions do differ in health and social characteristics. For instance, a much larger proportion of women identify as African, Caribbean or Black in Ontario (32\%) and Québec (46\%) compared with BC (8\%) where more women identify as Indigenous (45\%) and have histories of injection drug use (BC-63\% vs. Ontario-19\% vs. Québec-23\%) (data not shown). Women in Ontario are also younger, with a median age of 41 (IQR 34-49) versus 44 in BC (IQR 37-51) and 46 in Québec (IQR 38-53), and are less likely to be currently on cART (BC-89\% vs. Ontario- $75 \%$ vs. Québec-92\%) with a self-reported undetectable VL (BC-80\% vs. Ontario-71\% vs. Québec-87\%) (data not shown). However, the current analysis demonstrated high PPVs for the overall sample and specific sub-populations including women of varying ethnicities and drug use histories. The range in NPVs was lower and wider depending on demographics characteristics; thus, confidence in the true negative rate may vary by key factors such as education as shown in this analysis.

Another limitation is that we notified women during the screening process that we would be asking for their clinical information. Thus, the high validity here is likely not just a result of women knowing their VL but also because some women accessed this information from their clinic before the actual study visit. This is perhaps particularly true for women interviewed in a clinic setting. To examine this, we ran a sub-analysis among women who self-reported that their primary site of HIV medical care was Oak Tree Clinic [ $\mathrm{n}=132$ (39\% of sample)], one-third of whom were interviewed onsite $[n=41$ (31\%)], versus women who did not access this clinic. The PPVs for these two groups were similar [Oak Tree Clinic: 95.4 (95\% CI 89.6-98.5) vs. Non-Oak Tree Clinic: 92.6 (85\% CI 87.6-96.0)]. However, the NPVs were much higher for Oak Tree Clinic patients [91.3 (95\% CI 72.098.9)] compared with non-Oak Tree Clinic patients [71.4 (95\% CI 51.3-86.8)]. Thus, while prompting participants for clinical information does not appear to have altered the proportion of those undetectable that are able to correctly identify as such, likely given the high VL suppression rates to begin with, these data do suggest this screening procedure may have impacted accurate reporting of a detectable VL.
Finally, we also conducted a sub-analysis to determine whether the 18 participants who were unable to self-report their VL (either because they reported "don't know", "prefer not to answer", or "never received care/VL results") and thus excluded from this analysis were more, less, or equally likely to be undetectable than those who were included. Among these participants, 56\% $(\mathrm{n}=10)$ were detectable. This compares to only $18 \%(n=59)$ of those were included in this analysis. It is possible that these women did not feel comfortable sharing this personal information or were simply unaware owing to competing life demands preventing access to and engagement in care. All of these limitations are important to consider in research assessing VL levels.

Engagement in treatment, care, and support is critical to sustained viral suppression, and, in turn, improved individual health and HIV prevention [4-9]. Future research will be conducted by our team to assess the prevalence and predictors of HIV clinical outcomes in this cohort, the largest study of women living with HIV in Canada.

\section{Abbreviations \\ VL: viral load; CART: combination antiretroviral therapy; TasP: treatment as prevention; PPV: positive predictive value; NPV: negative predictive value; $L R+$ positive likelihood ratio; LR-: negative likelihood ratio; BC: British Columbia; CHIWOS: Canadian HIV Women's Sexual and Reproductive Health Cohort Study.}

\section{Authors' contributions}

AC and AK conceived of the research question. PS prepared the dataset. ED performed the statistical analysis. AC wrote the first draft of the manuscript. $\mathrm{AdP}, \mathrm{ML}, \mathrm{PS}, \mathrm{ED}, \mathrm{KW}, \mathrm{VN}, \mathrm{KB}, \mathrm{RH}$, and $\mathrm{AK}$ participated in the interpretation of the results and editing of the manuscript. All authors read and approved the final manuscript.

\section{Author details \\ ${ }^{1}$ Faculty of Health Sciences, Simon Fraser University, Burnaby, BC, Canada. ${ }^{2}$ Epidemiology and Population Health Program, British Columbia Centre for Excellence in HIV/AIDS, Vancouver, BC, Canada. ${ }^{3}$ Chronic Viral Illness Service, McGill University Health Centre, Montreal, QC, Canada. ${ }^{4}$ Depart- ment of Family Medicine, McGill University, Montreal, QC, Canada. ${ }^{5}$ Women's College Research Institute, Women's College Hospital, Toronto, ON, Canada. ${ }^{6}$ Faculty of Medicine, University of Toronto, Toronto, ON, Canada.}

\section{Acknowledgements}

The Canadian HIV Women's Sexual and Reproductive Health Cohort Study (CHIWOS) Research Team would like to especially thank all of the women living with HIV who participate in this research. We also thank the entire national team of Co-Investigators, Collaborators, and Peer Research Associates. We would like to acknowledge the national Steering Committee, the three provincial Community Advisory Boards, the national CHIWOS Aboriginal Advisory Board, and our partnering organizations for supporting the study, especially those who provide interview space and support to our Peer Research Associates.

\section{The CHIWOS Research Team:}

British Columbia: Aranka Anema (University of British Columbia), Denise Becker (Positive Living Society of British Columbia), Lori Brotto (University of British Columbia), Allison Carter (British Columbia Centre for Excellence in HIVI AIDS and Simon Fraser University), Claudette Cardinal (Simon Fraser University), Guillaume Colley (British Columbia Centre for Excellence in HIV/AIDS), Erin Ding (British Columbia Centre for Excellence), Janice Duddy (Pacific AIDS Network), Nada Gataric (British Columbia Centre for Excellence in HIV/AIDS), Robert S. Hogg 
(British Columbia Centre for Excellence in HIV/AIDS and Simon Fraser University), Terry Howard (Positive Living Society of British Columbia), Shahab Jabbari (British Columbia Centre for Excellence), Evin Jones (Pacific AIDS Network), Mary Kestler (Oak Tree Clinic, BC Women's Hospital and Health Centre), Andrea Langlois (Pacific AIDS Network), Viviane Lima (British Columbia Centre for Excellence in HIV/AIDS), Elisa Lloyd-Smith (Providence Health Care), Melissa Medjuck (Positive Women's Network), Cari Miller (Simon Fraser University), Deborah Money (Women's Health Research Institute), Valerie Nicholson (Simon Fraser University), Gina Ogilvie (British Columbia Centre for Disease Control), Sophie Patterson (Simon Fraser University), Neora Pick (Oak Tree Clinic, BC Women's Hospital and Health Centre), Eric Roth (University of Victoria), Kate Salters (Simon Fraser University), Margarite Sanchez (ViVA, Positive Living Society of British Columbia), Jacquie Sas (CIHR Canadian HIV Trials Network), Paul Sereda (British Columbia Centre for Excellence in HIV/AIDS), Marcie Summers (Positive Women's Network), Christina Tom (Simon Fraser University, BC), Clara Wang (British Columbia Centre for Excellence), Kath Webster (Simon Fraser University), Wendy Zhang (British Columbia Centre for Excellence in HIV/AIDS).

Ontario: Rahma Abdul-Noor (Women's College Research Institute), Jonathan Angel (Ottawa Hospital Research Institute), Fatimatou Barry (Women's College Research Institute), Greta Bauer (University of Western Ontario), Kerrigan Beaver (Women's College Research Institute), Anita Benoit (Women's College Research Institute), Breklyn Bertozzi (Women's College Research Institute), Sheila Borton (Women's College Research Institute), Tammy Bourque (Women's College Research Institute), Jason Brophy (Children's Hospital of Eastern Ontario), Ann Burchell (Ontario HIV Treatment Network), Allison Carlson (Women's College Research Institute), Lynne Cioppa (Women's College Research Institute), Jeffrey Cohen (Windsor Regional Hospital), Tracey Conway (Women's College Research Institute), Curtis Cooper (Ottawa Hospital Research Institute), Jasmine Cotnam (Women's College Research Institute), Janette Cousineau (Women's College Research Institute), Marisol Desbiens (Women's College Research Institute), Annette Fraleigh (Women's College Research Institute), Brenda Gagnier (Women's College Research Institute), Claudine Gasingirwa (Women's College Research Institute), Saara Greene (McMaster University), Trevor Hart (Ryerson University), Shazia Islam (Women's College Research Institute), Charu Kaushic (McMaster University), Logan Kennedy (Women's College Research Institute), Desiree Kerr (Women's College Research Institute), Maxime Kiboyogo (McGill University Health Centre), Gladys Kwaramba (Women's College Research Institute), Lynne Leonard (University of Ottawa), Johanna Lewis (Women's College Research Institute), Carmen Logie (University of Toronto), Shari Margolese (Women's College Research Institute), Marvelous Muchenje (Women's Health in Women's Hands), Mary (Muthoni) Ndung'u (Women's College Research Institute), Kelly O'Brien (University of Toronto), Charlene Ouellette (Women's College Research Institute), Jeff Powis (Toronto East General Hospital), Corinna Quan (Windsor Regional Hospital), Janet Raboud (Ontario HIV Treatment Network). Anita Rachlis (Sunnybrook Health Science Centre), Edward Ralph (St. Joseph's Health Care), Sean Rourke (Ontario HIV Treatment Network), Sergio Rueda (Ontario HIV Treatment Network), Roger Sandre (Haven Clinic), Fiona Smaill (McMaster University), Stephanie Smith (Women's College Research Institute), Tsitsi Tigere (Women's College Research Institute), Wangari Tharao (Women's Health in Women's Hands), Sharon Walmsley (Toronto General Research Institute), Wendy Wobeser (Kingston University), Jessica Yee (Native Youth Sexual Health Network), Mark Yudin (St-Michael's Hospital).

Quebec: Dada Mamvula Bakombo (McGill University Health Centre), Jean-Guy Baril (Université de Montréal), Nora Butler Burke (University Concordia), Pierrette Clément (McGill University Health Center), Janice Dayle, (McGill University Health Centre), Danièle Dubuc, (McGill University Health Centre), Mylène Fernet (Université du Québec à Montréal), Danielle Groleau (McGill University), Aurélie Hot (COCQ-SIDA), Marina Klein (McGill University Health Centre), Carrie Martin (Native Women's Shelter of Montreal), Lyne Massie, (Université de Québec à Montréal), Brigitte Ménard, (McGill University Health Centre), Nadia O'Brien (McGill University Health Centre and Université de Montréal), Joanne Otis (Université du Québec à Montréal), Doris Peltier (Canadian Aboriginal AIDS Network), Alie Pierre, (McGill University Health Centre), Karène Proulx-Boucher (McGill University Health Centre), Danielle Rouleau (Centre Hospitalier de l'Université de Montréal), Édénia Savoie (McGill University Health Centre), Cécile Tremblay (Centre Hospitalier de I'Université de Montréal), Benoit Trottier (Clinique I'Actuel), Sylvie Trottier (Centre Hospitalier Universitaire de Québec), Christos Tsoukas (McGill University Health Centre).

Other Canadian provinces or international jurisdictions: Jacqueline Gahagan (Dalhousie University), Catherine Hankins (University of Amsterdam),
Renee Masching (Canadian Aboriginal AIDS Network), Susanna OgunnaikeCooke (Public Health Agency of Canada).

All other CHIWOS Research Team Members who wish to remain anonymous.

\section{Competing interests}

The authors declare that they have no competing interests.

\section{Ethics approval and consent to participate}

All Principal Investigators'institutional Research Ethics Boards granted ethical approval including Women's College Hospital, McGill University Health Centre, and in BC, Simon Fraser University and the University of British Columbia/ Providence Health (Ethical Approval Numbers: 201250959 and H12-03326). Ethical approval was also sought and granted from hospitals and AIDS Service Organizations if recruitment occurred there. All participants provided consent (written or oral in the case of phone interviews) to participate.

\section{Funding}

CHIWOS is funded by the Canadian Institutes of Health Research (CIHR, MOP11 1041); the CIHR Canadian HIV Trials Network (CTN 262); the Ontario HIV Treatment Network (OHTN); and the Academic Health Science Centres (AHSC) Alternative Funding Plans (AFP) Innovation Fund. Allison Carter received a Doctoral Research Scholarship from the Canadian Institutes of Health Research (CIHR) and the Canadian Association for HIV Research (CAHR). Alexandra de Pokomandy received salary support through the Fonds de Recherche du Quebéc-Santé (FRQS) (Chercheur-boursier clinicien). Angela Kaida received salary support through a Tier 2 Canada Research Chair in Global Perspectives on HIV and Sexual and Reproductive Health.

Received: 10 October 2016 Accepted: 17 March 2017

Published online: 24 March 2017

\section{References}

1. Günthard HF, Saag MS, Benson CA, Del Rio C, Eron JJ, Gallant JE, et al. Antiretroviral drugs for treatment and prevention of HIV infection in adults: 2016 recommendations of the International Antiviral Society-USA Panel. JAMA. 2016;316(2):191-210.

2. Insight Start Study Group. Initiation of antiretroviral therapy in early asymptomatic HIV infection. N Engl J Med. 2015;2015(373):795-807.

3. Temprano ANRS, 12136 Study Group. A trial of early antiretrovirals and isoniazid preventive therapy in Africa. N Engl J Med. 2015;2015(373):808-22.

4. Hogg RS, Heath KV, Yip B, Craib KJ, O'Shaughnessy MV, Schechter MT, et al. Improved survival among HIV-infected individuals following initiation of antiretroviral therapy. JAMA. 1998;279(6):450-4.

5. Cohen MS, Chen YQ, McCauley M, Gamble T, Hosseinipour MC, Kumarasamy $\mathrm{N}$, et al. Prevention of HIV-1 infection with early antiretroviral therapy. N Engl J Med. 2011;365(6):493-505.

6. Montaner JS. Treatment as prevention - a double hat-trick. Lancet. 2011:378(9787):208-9.

7. Montaner JS, Lima VD, Harrigan PR, Lourenço L, Yip B, Nosyk B, et al. Expansion of HAART coverage is associated with sustained decreases in HIV/AIDS morbidity, mortality and HIV transmission: the "HIV Treatment as Prevention" experience in a Canadian setting. PLoS ONE. 2014;9(2):e87872

8. Rodger A, Bruun T, Cambiano V, Vernazza P, Estrada V, Van Lunzen J, et al., editors. HIV transmission risk through condomless sex if HIV + partner on suppressive ART: PARTNER study (Abstract 153LB). 21st conference on retroviruses and opportunistic infections (CROI 2014). Boston; 2014.

9. Rodger A, editor. Association between sexual activity without condoms and risk of HIV transmission in serodifferent couples when the HIVpositive partner is using suppressive antiretroviral therapy: the PARTNER study. 21st international AIDS conference. Durban; 2016 (Abstract TUAC0206)

10. Lourenço L, Lima VD, Heath K, Nosyk B, Gilbert M, Colley G, et al. Process monitoring of an HIV treatment as prevention program in British Columbia, Canada. JAIDS J Acquir Immune Defic Syndr. 2014;67(3):e94-109. 
11. UNAIDS. 909090 An ambitious treatment target to help end the AIDS epidemic. Geneva: UNAIDS; 2014.

12. Cogswell HA, Ohadi E, Avila C. Viral-load point-of-care technologies to achieve an AIDS-free generation. Future Microbiol. 2016;11(1):5-9.

13. Loutfy M, Greene S, Kennedy VL, Lewis J, Thomas-Pavanel J, Conway T, et al. Establishing the Canadian HIV Women's Sexual and Reproductive Health Cohort Study (CHIWOS): operationalizing community-based research in a large national quantitative study. BMC Med Res Methodol. 2016;16(1):101.

14. Kaida A CA, Lemay J, O'Brien N, Greene S, Nicholson V, et al. CHIWOS Research Team. Hiring, training, and supporting peer researchers: Operationalizing community-based research principles within epidemiological studies by, with, and for women living with HIV. 23rd Annual Canadian conference on HIV/AIDS Research (CAHR 2014); St. John's, NewfoundlandMay 1-4, 2014 (Abstract O106, Oral).

15. Webster K, Carter A, Proulx-Boucher K, Dubuc D, Nicholson V, Beaver K, et al. Strategies for recruiting women living with HIV in community-based research: lessons from Canada progress in community health partnerships: research, education, and action (Under review).

16. Palmer AK, Klein MB, Raboud J, Cooper C, Hosein S, Loutfy M, et al. Cohort profile: the Canadian observational cohort collaboration. Int J Epidemiol. 2011;40(1):25-32
17. Altman DG, Bland JM. Statistics notes: diagnostic tests 2: predictive values. BMJ. 1994;309(6947):102.

18. McGee S. Simplifying likelihood ratios. J Gen Intern Med. 2002;17(8):647-50.

19. McMahon JH, Elliott JH, Bertagnolio S, Kubiak R, Jordan MR. Viral suppression after 12 months of antiretroviral therapy in low-and middleincome countries: a systematic review. Bull World Health Organ. 2013;91(5):377-85.

20. Carter A, Min JE, Chau W, Lima VD, Kestler M, Pick N, et al. Gender inequities in quality of care among HIV-positive individuals initiating antiretroviral treatment in British Columbia, Canada (2000-2010). PLoS ONE. 2014;9(3):e92334.

21. Cescon A, Cooper C, Chan K, Palmer A, Klein M, Machouf N, et al. Factors associated with virological suppression among HIV-positive individuals on highly active antiretroviral therapy in a multi-site Canadian cohort. HIV Med. 2011;12(6):352-60.

22. Wessman M, Aho I, Thorsteinsson K, Storgaard M, Johansen IS, Lunding $\mathrm{S}$, et al. Perception of sexuality and fertility in women living with HIV: a questionnaire study from two Nordic countries. J Int Aids Soc 2015;18.

23. Blank AE, Fletcher J, Verdecias N, Garcia I, Blackstock O, Cunningham C. Factors associated with retention and viral suppression among a cohort of HIV+ women of color. AIDS Patient Care STDs. 2015;29(S1):S27-35.

\section{Submit your next manuscript to BioMed Central and we will help you at every step:}

- We accept pre-submission inquiries

- Our selector tool helps you to find the most relevant journal

- We provide round the clock customer support

- Convenient online submission

- Thorough peer review

- Inclusion in PubMed and all major indexing services

- Maximum visibility for your research

Submit your manuscript at www.biomedcentral.com/submit 